\title{
Antibiotic Combinations with Daptomycin for Treatment of Staphylococcus aureus Infections
}

\author{
Kristina Nadrah and Franc Strle \\ Department of Infectious Diseases, University Medical Centre Ljubljana, Japljeva 2, 1525 Ljubljana, Slovenia \\ Correspondence should be addressed to Kristina Nadrah, kristina.nadrah@kclj.si
}

Received 19 November 2010; Accepted 23 January 2011

Academic Editor: Athanassios Tsakris

Copyright (๑) 2011 K. Nadrah and F. Strle. This is an open access article distributed under the Creative Commons Attribution License, which permits unrestricted use, distribution, and reproduction in any medium, provided the original work is properly cited.

Daptomycin is a lipopeptide antibiotic with a unique mechanism of action on Gram-positive bacteria. It is approved for treatment of skin and soft-tissue infections with Gram-positive bacteria, bacteraemia and right-sided infective endocarditis caused by Staphylococcus aureus. Diminishing susceptibility of $S$. aureus to daptomycin during treatment of complicated infections and clinical failure have been described. Combinations of daptomycin with other antibiotics including gentamicin, rifampin, betalactams, trimethoprim/sulfamethoxazole (TMP-SMX), or clarithromycin present a new approach for therapy. In vitro and animal studies have shown that such combinations may, in some cases, be superior to daptomycin monotherapy. In this paper we focus on the antibiotic combinations for complicated S. aureus infections.

\section{Introduction}

Daptomycin, an antibiotic with a new mechanism of action and low occurrence of spontaneous resistance, came to market in 2003 in the USA and in 2006 in Europe. In spite of its many promises for treatment of infections caused by Gram-positive bacteria, reports on clinical failure and diminished in vitro susceptibility soon came forward. Alongside, it became clear that daptomycin monotherapy of biofilm-related and deep-seated infections is often not effective. Due to limited clinical settings in which daptomycin is effective, diminishing susceptibility to daptomycin, emerging resistance to linezolid, and slow development of new antibiotics, clinicians have difficulties treating serious Staphylococcus aureus infections. Therefore, combinations of daptomycin with other antibiotics are extensively studied as a potential new therapeutic strategy. In this review, we will focus on the antibiotic combinations for complicated $S$. aureus infections.

\section{Daptomycin Pharmacology}

Daptomycin is a novel lipopeptide antibiotic approved for treatment of complicated skin and soft-tissue infections caused by Gram-positive bacteria, and for S. aureus bacteraemia and right-sided endocarditis [1]. It is not active in low respiratory tract infections, because lung surfactant forms complexes with daptomycin thereby inactivating it [2].

Daptomycin mechanism of action is complex and not entirely understood. Research so far indicates that it acts on cell membrane $[3,4]$ and also inhibits the synthesis of lipoteichoic acid, necessary for cell wall synthesis [4].

Daptomycin structure consists of an anionic core and a lipophilic tail. By binding divalent calcium and forming $\mathrm{Ca}^{2+}$-complexes, the net charge of the molecule becomes positive and thus enables electrostatic interactions with negatively charged cell membrane. It then binds to cell membrane, where it forms oligomers and subsequently channels through which intracellular ions, like potassium, leak out of the cell, diminishing cell membrane negative potential and causing cell death [3]. This initial model was later modified according to the observation that daptomycin forms micelle-like structures in the medium and binds to the membrane in the already oligomerized form [5]. However, Hobbs et al. found that changes in dissipation of membrane potential and leakage of intracellular material occur rather late, after cell death, and with no significant alterations in membrane integrity [6]. Similarly, no significant cell lysis was 
found by electron microscopy and the membrane integrity probes used on $S$. aureus treated in vitro with daptomycin [7]. In addition, analogous to cell wall active antibiotics, daptomycin was found to upregulate cell wall stress stimulon genes [8]. The gene expression profile of S. aureus after being exposed to daptomycin is similar to profiles developed after exposure to cell wall active antibiotics, such as beta-lactams, as well as to compounds which disrupt cell membrane, like carbonyl cyanide $m$-chlorophenylhydrazone [8]. Thus, beside acting on the cell membrane, daptomycin likely acts on several other targets.

Daptomycin activity is sensitive to the inoculum of the infectious micro-organism [9]. This is probably due to the decrease of the local effective antibiotic concentration at high inoculum [10]. Therefore, sufficient serum concentrations are essential for clearance of bacteria from the infection site.

The current susceptibility cutoff MIC of $S$. aureus isolates to daptomycin is set at $1 \mathrm{mg} / \mathrm{L}$ [11]. In some cases, susceptibility profile is heterogeneous [12]. No MIC creep like in the case of vancomycin has been noticed [13-15], even in the isolates collected over several decades [11]. Since unequivocal criteria for resistance have not been defined yet, the term non-susceptibility is used instead of resistance.

\section{Mechanisms of Non-susceptibility to Daptomycin}

Strains of $S$. aureus non-susceptible to daptomycin have been obtained from clinical cases, by in vitro selection, and by chemical mutagenesis. Frequency of spontaneous daptomycin resistance in S. aureus is low $\left(10^{-10}\right)$ [12]. Serial passages in subinhibitory concentrations of daptomycin give rises of MICs by a factor of $8-32$; the same is valid for chemical mutagenesis $[12,16,17]$.

Several genes have been implicated in S. aureus nonsusceptibility to daptomycin. Overexpression and mutations in $m p r F$ [18-20] which encodes lysyl-phosphatidylglycerol (LPG) synthetase and flippase, and $y y c \mathrm{G}$ which encodes histidine kinase in a two-component sensor regulatory system of $\mathrm{YycF} / \mathrm{YycG}[16,20]$ were identified in clinical isolates and laboratory-derived strains, while $\operatorname{rpoB}[20,21]$ and rpoC [16] which encode $\beta$ and $\beta^{\prime}$ subunits of RNA polymerase were detected only in in vitro selected laboratory non-susceptible strains. In vitro insertional mutation of $\operatorname{csp} \mathrm{B}$ [22], a cold shock gene, led to increased susceptibility to daptomycin in a daptomycin non-susceptible strain of $S$. aureus. Several mutants obtained in vitro and some of the clinical isolates contain at least one of these genetic changes; a combination of the genetic alterations seems to have an additive effect on the MIC value [20]. However, some daptomycin non-susceptible strains do not have any of these alterations $[23,24]$, indicating that the mechanism of "resistance" is probably multifactorial.

The phenotypic alterations in non-susceptible $S$. aureus can be grouped into (1) changes in cell wall structure and turnover; (2) changes in membrane composition, membrane structure, and membrane potential; (3) modifications in sensitivity to depolarization, autolysis, and permeabilization.
In some cases, thicker cell wall had been correlated to nonsusceptibility $[18,20,21,25]$, but this was not a uniform finding; for example, Yang et al. found no changes in cell wall thickness in a clinical meticillin-resistant S. aureus (MRSA) isolate with diminished susceptibility to daptomycin which developed during treatment [19]. S. aureus strains nonsusceptible to daptomycin had an increased synthesis of LPG and increased translocation of LPG to the outer membrane, and hence modifications in membrane fluidity and electrostatic potential $[19,20,26]$. A loss of an unidentified $81 \mathrm{kD}$ membrane protein has also been described in a nonsusceptible clinical isolate [17].

So far, most cases of clinically acquired non-susceptibility of $S$. aureus to daptomycin occurred in a setting of inadequate dosing [17] and/or deep-seated, high-inoculum, and biofilm-related infective, such as infectious endocarditis (IE) $[17,19,26,27]$ or bone infections [24]. In these cases, the effective concentration of daptomycin at the site of the highest bacterial density is low [10], and activity is further diminished by the stationary phase of bacteria in biofilm which has been associated with such infections [28].

\section{Relationship between Diminished Susceptibility to Vancomycin and Daptomycin}

Diminished susceptibility of $S$. aureus to vancomycin has been associated with a development of diminished susceptibility to daptomycin. This has been established for multidrug resistant (MDR) S. aureus, for MRSA, as well as for meticillin-susceptible $S$. aureus (MSSA). Daptomycin is often prescribed for treatment of MDR S. aureus infections if vancomycin therapy fails. Clinical experience indicates that strains of $S$. aureus with diminished susceptibility to vancomycin develop a diminished susceptibility to daptomycin during treatment $[27,29-31]$ or even in absence of daptomycin exposure $[32,33]$. Several studies found that diminished susceptibility to vancomycin in MRSA is associated with diminished susceptibility to daptomycin [32], and, according to some reports, that it correlates well with increased cell wall thickness [25, 27]. The highest MICs of vancomycin intermediate S. aureus (VISA)/MRSA, observed in deep-seated infections such as septic arthritis and osteomyelitis, are often associated with higher MICs for daptomycin or even with non-susceptibility to daptomycin [33]. In the case of MRSA IE and septic thrombophlebitis, the patient's strain developed non-susceptibility to glycopeptides during treatment with glycopeptides, and, after switching therapy to daptomycin, a non-susceptibility to daptomycin. MRSA was successfully eradicated from the bloodstream only after therapy with linezolid and fusidic acid [27]. A similar relationship was found for MSSA: diminished susceptibility to vancomycin which developed during therapy of patients with osteomyelitis [34] or IE [26] was associated with a higher MIC to daptomycin even though the patients had never received it. Subsequent analysis found that vancomycin and daptomycin exhibited a reduced bactericidal activity towards the non-susceptible 
TABLE 1: Data on previous vancomycin/daptomycin therapy in MRSA and MSSA clinical isolates non-susceptible to daptomycin.

\begin{tabular}{|c|c|c|c|c|c|c|c|}
\hline Strain & Infection & $\begin{array}{l}\text { Previous } \\
\text { VAN therapy } \\
\text { (days) }\end{array}$ & $\begin{array}{l}\text { Reason for } \\
\text { change }\end{array}$ & DAP therapy & $\begin{array}{l}\text { MIC of DNS } \\
\text { strain (days*) }\end{array}$ & Outcome & Ref. \\
\hline MRSA & IE & Yes (No data) & Failure & Yes & $\begin{array}{l}\text { MIC } 2^{b}(\mathrm{No} \\
\text { data) }\end{array}$ & No data & $\begin{array}{l}{[26](\text { Case }} \\
\text { report) }\end{array}$ \\
\hline MRSA & IE & Yes $\left(47^{* *}\right)$ & Failure & Yes & $\operatorname{MIC~} 4^{\mathrm{a}}(14)$ & $\begin{array}{l}\text { Died (C. albicans septic } \\
\text { shock) }\end{array}$ & $\begin{array}{l}{[27] \text { (Case }} \\
\text { report) }\end{array}$ \\
\hline MRSA & IE & Yes $\left(46^{* * *}\right)$ & Failure & $\begin{array}{l}6 \mathrm{mg} / \mathrm{kg} \\
\mathrm{q} 24 \mathrm{~h}\end{array}$ & $\operatorname{MIC~} 4^{\mathrm{a}}(24)$ & $\begin{array}{l}\text { Survived on alternative } \\
\text { treatment }\end{array}$ & $\begin{array}{l}{[30](\text { Case }} \\
\text { report) }\end{array}$ \\
\hline MRSA & BSI & Yes (15) & Failure & $\begin{array}{l}6 \mathrm{mg} / \mathrm{kg} \\
\mathrm{q} 24 \mathrm{~h}, \text { then } \\
8 \mathrm{mg} / \mathrm{kg} \\
\mathrm{q} 24 \mathrm{~h}\end{array}$ & $\operatorname{MIC~} 4^{\mathrm{a}}(6)$ & Died & $\begin{array}{l}{[31] \text { (Case }} \\
\text { report) }\end{array}$ \\
\hline MRSA & BSI & Yes (No data) & No change & No & $\begin{array}{l}\text { MIC 2a (No } \\
\text { data) }\end{array}$ & No data & $\begin{array}{l}{[32] \text { (Case }} \\
\text { series) }\end{array}$ \\
\hline MRSA & UTI & Yes (12) & Failure & $\begin{array}{l}6 \mathrm{mg} / \mathrm{kg} \\
\mathrm{q} 24 \mathrm{~h}\end{array}$ & $\operatorname{MIC~} 4^{\mathrm{a}}(7)$ & Died & $\begin{array}{l}{[29] \text { (Case }} \\
\text { report) }\end{array}$ \\
\hline MSSA & $\mathrm{OM}$ & Yes (60) & Failure & No & $\begin{array}{l}\mathrm{MIC} 4^{\mathrm{a}}(\mathrm{No} \\
\text { data) }\end{array}$ & $\begin{array}{l}\text { Survived on alternative } \\
\text { treatment(nafcillin } \\
\text { +rifampin) }\end{array}$ & $\begin{array}{l}{[34] \text { (Case }} \\
\text { report) }\end{array}$ \\
\hline
\end{tabular}

DAP: daptomycin; VAN: vancomycin; DNS: daptomycin non-susceptible; UTI: urinary tract infection; BSI: bloodstream infection; IE: infective endocarditis; OM: osteomyelitis. MRSA: meticillin-resistant S. aureus; MSSA: meticillin-susceptible $S$. aureus; * duration (days) of treatment with daptomycin prior to isolate was obtained; ${ }^{* *}$ vancomycin for 12 days, then teicoplanin 35 days; ***2 courses: 6 weeks initially, additional 4 days after relapse; (a) broth microdilution (b) Etest. All initial isolates were susceptible to daptomycin; MIC: minimal inhibitory concentration (mg/L).

examined strain and a lesser degree of its chemical autolysis was observed [34]. Nevertheless, in vitro time-kill studies show that daptomycin retains bactericidal activity in spite of increased MIC provided that the concentrations exceed MIC by several times [31] (Table 1).

However, not all studies confirmed that diminished susceptibility of $S$. aureus to vancomycin is associated with diminished susceptibility to daptomycin. In a retrospective study of the influence of previous vancomycin therapy on MIC and bactericidal activity of daptomycin and vancomycin in S. aureus (isolates from patients who received vancomycin within 30 days prior to development of MRSA bacteraemia were compared with isolates from those who did not receive the drug), higher MICs and decreased killing was established only for vancomycin but not for daptomycin [35].

\section{Antibiotic Combinations with Daptomycin}

In some groups of patients, such as those infected with $S$. aureus strains which have diminished susceptibility to both vancomycin and daptomycin, especially in the case of MDR S. aureus, or in patients with deep-seated daptomycin susceptible $S$. aureus infections, monotherapy with daptomycin at approved doses $(4-6 \mathrm{mg} / \mathrm{kg} /$ day $)$ is frequently not effective and may even yield non-susceptible isolates. In such patients, treatment options are highly limited, and addition of another antibiotic to daptomycin may be beneficial. The combinations can be divided into three groups: (1) classical combinations of daptomycin and gentamicin or rifampicin; (2) combinations of daptomycin and betalactams; (3) combinations of daptomycin with bacteriostatic antibiotics such as trimethoprim/sulfamethoxazole (TMPSMX) or clarithromycin. Findings on in vivo and in vitro synergy of antibiotic combinations are depicted on Tables 2 and 3.

\subsection{Combinations of Daptomycin with Gentamicin or Rifampin}

5.1.1. Infective Endocarditis. Standard treatment of left-sided IE caused by $S$. aureus usually includes two antibiotics with a synergistic bactericidal action, typically a cell wall synthesis inhibitor and an aminoglycoside, with the addition of rifampicin in case of infected prosthetic material [36]. Study on a small number of severely ill patients with left-sided S. aureus endocarditis revealed that daptomycin monotherapy was inferior to standard therapy, and that both treatment groups had a very low success rate $(11 \%$ and $22 \%$, resp.) [1]. A retrospective analysis of data from daptomycin outcomes registry $[37,38]$ suggested that the overall success of treatment of the left-sided IE caused by $S$. aureus may be as high as $60 \%$ with the majority of the patients receiving daptomycin in combination with other antibiotics. These findings were a stimulus for the assessment of the efficacy of daptomycin in combination with other antibiotics, initially with gentamicin or rifampicin, that is, antibiotics used for standard treatment.

Combination of daptomycin with gentamicin or rifampicin was tested in vitro as well as in in vivo animal models of IE [39]. Etest with MSSA/heterogeneous glycopeptide-intermediate $S$. aureus (hGISA) and MRSA/GISA showed synergy of daptomycin-gentamicin 
TABLE 2: Information on in vivo synergy of antibiotic combinations.

\begin{tabular}{|c|c|c|c|c|}
\hline Model & Strain & Combination & Observation & Ref. \\
\hline \multirow[t]{2}{*}{$\begin{array}{l}\text { Experimental model } \\
\text { of IE }\end{array}$} & \multirow[t]{2}{*}{ MRSA } & $\begin{array}{l}\text { Daptomycin } 6 \mathrm{mg} / \mathrm{kg} \mathrm{q} 24 \mathrm{~h}+\text { rifampin } \\
300 \mathrm{mg} \mathrm{q} 8 \mathrm{~h}\end{array}$ & \multirow[t]{2}{*}{$\begin{array}{l}\text { Rifampin and gentamicin } \\
\text { antagonized/delayed the bactericidal } \\
\text { activity of daptomycin }\end{array}$} & \multirow[t]{2}{*}{ [39] } \\
\hline & & $\begin{array}{l}\text { Daptomycin } 6 \mathrm{mg} / \mathrm{kg} \text { q } 24 \mathrm{~h}+\text { gentamicin } \\
1.3 \mathrm{mg} / \mathrm{kg} \mathrm{q} 12 \mathrm{~h}\end{array}$ & & \\
\hline \multirow[t]{2}{*}{ Rabbit model of IE } & \multirow[t]{2}{*}{ MRSA } & $\begin{array}{l}\text { Daptomycin } 6 \mathrm{mg} / \mathrm{kg} \mathrm{q} 24 \mathrm{~h}+\text { gentamicin } \\
1 \mathrm{mg} / \mathrm{kg} \mathrm{q} 8 \mathrm{~h}\end{array}$ & $60 \%$ vegetations sterilized & \multirow[t]{2}{*}[41]{} \\
\hline & & $\begin{array}{l}\text { Daptomycin } 6 \mathrm{mg} / \mathrm{kg} \mathrm{q} 24 \mathrm{~h}+\text { rifampin } \\
300 \mathrm{mg} \mathrm{q} 8 \mathrm{~h}\end{array}$ & $20 \%$ vegetations sterilized & \\
\hline Rabbit model of IE & DNS MRSA & $\begin{array}{l}\text { Daptomycin } 12 \mathrm{mg} / \mathrm{kg} \mathrm{q} 24 \mathrm{~h}+\text { oxacillin } \\
200 \mathrm{mg} / \mathrm{kg} \mathrm{q} 8 \mathrm{~h}\end{array}$ & Enhanced bacterial clearance from tissues & {$[56]$} \\
\hline Case report on IE & $\begin{array}{l}\text { MRSA with } \\
\text { progressive loss } \\
\text { of susceptibility } \\
\text { during } \\
\text { treatment }\end{array}$ & $\begin{array}{l}\text { Treated with vancomycin, then } \\
\text { daptomycin } 6 \mathrm{mg} / \mathrm{kg} \mathrm{q} 24 \mathrm{~h} \text {, then } \\
\text { daptomycin } 12 \mathrm{mg} / \mathrm{kg} \mathrm{q} 24 \mathrm{~h}+\text { rifampin } \\
300 \mathrm{mg} \mathrm{q} 8 \mathrm{~h}\end{array}$ & Clinical success & {$[42]$} \\
\hline \multirow{2}{*}{$\begin{array}{l}\text { Rabbit acute } \\
\text { osteomyelitis model }\end{array}$} & \multirow{2}{*}{ MRSA } & Daptomycin $6 \mathrm{mg} / \mathrm{kg} \mathrm{q} 24 \mathrm{~h}$ & Failure to eradicate bacteria & \multirow[t]{2}{*}[50]{} \\
\hline & & $\begin{array}{l}\text { Daptomycin } 6 \mathrm{mg} / \mathrm{kg} \mathrm{q} 24 \mathrm{~h}+\text { rifampin } \\
20^{\mathrm{a}} \mathrm{mg} / \mathrm{kg} \mathrm{q} 12 \mathrm{~h}\end{array}$ & $\begin{array}{l}\text { Eradication of bacteria: bone } 100 \% \text {, bone } \\
\text { marrow } 89 \% \text {, and joint fluid } 44 \%\end{array}$ & \\
\hline \multirow{3}{*}{$\begin{array}{l}\text { Guinea pig } \\
\text { foreign-body } \\
\text { infection model }\end{array}$} & \multirow{3}{*}{ MRSA } & $\begin{array}{l}\text { Daptomycin } 20 \mathrm{mg} / \mathrm{kg} \mathrm{q} 24 \mathrm{~h}+\text { rifampin } \\
12.5 \mathrm{mg} / \mathrm{kg} \mathrm{q} 12 \mathrm{~h}\end{array}$ & $25 \%$ cure & \multirow[t]{3}{*}[51]{} \\
\hline & & $\begin{array}{l}\text { Daptomycin } 30^{\mathrm{b}} \mathrm{mg} / \mathrm{kg} \mathrm{q} 24 \mathrm{~h}+\text { rifampin } \\
12.5 \mathrm{mg} / \mathrm{kg} \mathrm{q} 12 \mathrm{~h}\end{array}$ & $67 \%$ cure & \\
\hline & & $\begin{array}{l}\text { Vancomycin } 15 \mathrm{mg} / \mathrm{kg} \mathrm{q} 12 \mathrm{~h}+\text { rifampin } \\
12.5 \mathrm{mg} / \mathrm{kg} \mathrm{q} 12 \mathrm{~h}\end{array}$ & $8 \%$ cure & \\
\hline \multirow{3}{*}{$\begin{array}{l}\text { Rat foreign-body } \\
\text { infection model }\end{array}$} & \multirow{3}{*}{ MRSA } & $\begin{array}{l}\text { Daptomycin } 100^{\mathrm{c}} \mathrm{mg} / \mathrm{kg} \mathrm{q} 24 \mathrm{~h}+ \\
\text { rifampin } 25 \mathrm{mg} / \mathrm{kg} \mathrm{q} 12 \mathrm{~h}\end{array}$ & $94 \%$ cure & \multirow[t]{3}{*}[53]{} \\
\hline & & $\begin{array}{l}\text { Daptomycin } 45 \mathrm{mg} / \mathrm{kg} \mathrm{q} 24 \mathrm{~h}+\text { rifampin } \\
25 \mathrm{mg} / \mathrm{kg} \mathrm{q} 12 \mathrm{~h}\end{array}$ & $64 \%$ cure & \\
\hline & & $\begin{array}{l}\text { Vancomycin } 50 \mathrm{mg} / \mathrm{kg} \mathrm{q} 12 \mathrm{~h}+\text { rifampin } \\
25 \mathrm{mg} / \mathrm{kg} \mathrm{q} 12 \mathrm{~h}\end{array}$ & $25 \%$ cure & \\
\hline \multirow{2}{*}{$\begin{array}{l}\text { In vitro PK/PD model } \\
\text { of SEV }\end{array}$} & \multirow{2}{*}{ DNS MRSA } & $\begin{array}{l}\text { Daptomycin } 6 \mathrm{mg} / \mathrm{kg} \mathrm{q} 24 \mathrm{~h}+\mathrm{TMP} / \mathrm{SMX} \\
160 / 800 \mathrm{mg} \mathrm{q} 12 \mathrm{~h}\end{array}$ & \multirow[t]{2}{*}{ Bactericidal activity reached at 8 hours } & \multirow[t]{2}{*}[59]{} \\
\hline & & $\begin{array}{l}\text { Daptomycin } 6 \mathrm{mg} / \mathrm{kg} \mathrm{q} 24 \mathrm{~h}+\text { cefepime } \\
2 \mathrm{~g} \mathrm{q} 8 \mathrm{~h}\end{array}$ & & \\
\hline $\begin{array}{l}\text { In vitro } \mathrm{PK} / \mathrm{PD} \text { model } \\
\text { of } \mathrm{SEV}\end{array}$ & MSSA, MRSA & $\begin{array}{l}\text { Daptomycin } 6-8 \mathrm{mg} / \mathrm{kg} \mathrm{q} 24 \mathrm{~h}+ \\
\text { gentamicin } 5 \mathrm{mg} / \mathrm{kg} \text { as a single dose; or }+ \\
\text { gentamicin } 1 \mathrm{mg} / \mathrm{kg} \mathrm{q} 8 \mathrm{~h} \text {, three doses only }\end{array}$ & $\begin{array}{l}\text { Daptomycin } 6-8 \mathrm{mg} / \mathrm{kg} / \text { day combined } \\
\text { with one } 5 \mathrm{mg} / \mathrm{kg} \text { dose of gentamicin was } \\
\text { bactericidal in } 4 \mathrm{~h}\end{array}$ & {$[66]$} \\
\hline $\begin{array}{l}\text { In vitro } \mathrm{PK} / \mathrm{PD} \text { model } \\
\text { of SEV }\end{array}$ & GISA, MRSA & $\begin{array}{l}\text { Daptomycin 3-6 mg/kg q24h }+ \\
\text { arbekacin } 100 \mathrm{mg} \mathrm{q12} \mathrm{h}\end{array}$ & $\begin{array}{l}\text { Synergy, but regrowth in } 48 \mathrm{~h} \text { in the } \\
\text { regimen with daptomycin } 4 \mathrm{mg} / \mathrm{kg} / \text { day }\end{array}$ & {$[67]$} \\
\hline
\end{tabular}

Equivalent dosing to (a) rifampin $10 \mathrm{mg} / \mathrm{kg}$ q12 h oral administration (b) daptomycin $6 \mathrm{mg} / \mathrm{kg} \mathrm{q} 24 \mathrm{~h}$ (c) daptomycin $10 \mathrm{mg} / \mathrm{kg} \mathrm{q} 24 \mathrm{~h}$ in humans; PK/PD: pharmacokinetic/pharmacodynamic; SEV: simulated endocardial vegetations; TMP/SMX: trimethoprim-sulfamethoxazole; IE: infective endocarditis, DNS: daptomycin non-susceptible; MRSA: meticillin-resistant S. aureus; GISA: glycopeptide-intermediate S. aureus.

combination for both types of strains used while the time-kill studies confirmed the synergy only in the case of MSSA/hGISA [40]. Combinations of daptomycin and rifampicin were indifferent in both assays [40]. In an in vitro pharmacodynamic model of IE with simulated endocardial vegetations and daptomycin susceptible MRSA strain, the addition of rifampicin and gentamicin substantially delayed or even antagonized the bactericidal effect of daptomycin [39]. Similar results were found in an in vivo rabbit model of aortic IE caused by daptomycin-susceptible MRSA: not only was the addition of gentamicin or rifampicin to daptomycin at $6 \mathrm{mg} / \mathrm{kg} / \mathrm{day}$ of no beneficial value, the combination treatment was less successful in lowering the bacterial cell counts than daptomycin monotherapy [41].

However, in a clinical case of a mitral valve endocarditis with heterogeneous population of $S$. aureus, where one population was fully susceptible to vancomycin and daptomycin and the other non-susceptible, the addition of rifampicin to a high dose of daptomycin $(12 \mathrm{mg} / \mathrm{kg} /$ day $)$ resulted in treatment success with sterile blood cultures in 72 hours [42]. 
5.1.2. Bone Infections, Foreign-Body Infections, and Biofilms. In general, antibiotic combinations with rifampicin more successfully treat prosthetic devices-related staphylococcal infections $[43,44]$ and more efficiently eradicate $S$. aureus biofilm than monotherapy without rifampicin [45]. Because penetration of antistaphylococcal antibiotics into the biofilm is variable [46] and the bacteria are in a senescent state [28], serum concentrations of the anti-staphylococcal drug may play a role in successful eradication of staphylococci from a biofilm [46]. In addition, activity of several antibiotics, including daptomycin, is concentration dependent, and thus enhanced with higher serum concentrations [4]. Penetration of rifampicin [47] and daptomycin [48] in an S. epidermidis biofilm is good, but, in the absence of data, we may only speculate that the same is valid for S. aureus biofilms.

Information on the efficacy of daptomycin alone and in combination with rifampicin for treatment of $S$. aureus bone and foreign-body infections is rather incomplete, and limited to in vitro testing and in vivo animal model investigations; the findings of the studies are not completely unequivocal. An in vivo study using a rat model of foreignbody infection with a fully susceptible MSSA has found that daptomycin monotherapy at low doses (corresponding to human dose of $4 \mathrm{mg} / \mathrm{kg} /$ day) is as effective as vancomycin but can lead to diminished susceptibility to daptomycin which develops during treatment [49]. In an animal model of acute osteomyelitis caused by MRSA susceptible to vancomycin, daptomycin, and rifampicin, monotherapy with daptomycin $(6 \mathrm{mg} / \mathrm{kg} /$ day $)$ was not successful and in some cases diminished susceptibility occurred during therapy. Addition of rifampicin resulted in a more frequent eradication of bacteria from the bone and prevented the emergence of resistant strains [50]. Similarly, in a guinea pig foreign-body infection model with MRSA susceptible to daptomycin, the addition of rifampicin to an intermediate dose of daptomycin $(6 \mathrm{mg} / \mathrm{kg} /$ day $)$ resulted in treatment success in two thirds of the animals whereas monotherapy was ineffective [51]. Higher doses of daptomycin seem to be better in eradicating the bacteria, but combinations with rifampicin are even more efficient. A comparison of daptomycin (corresponding to human dose of $10 \mathrm{mg} / \mathrm{kg} /$ day) and rifampicin monotherapy in a rat model of foreign-body infection with MRSA susceptible to daptomycin and rifampicin has shown that both therapies are equally effective, but rifampicin resistance developed during treatment in 60\% [52]. In a rat model of foreign-body infection with MRSA susceptible to vancomycin, daptomycin, and rifampicin, monotherapy with a high dose of daptomycin $(10 \mathrm{mg} / \mathrm{kg} /$ day $)$ effectively decreased bacterial cell counts (over $3 \log \mathrm{CFU} / \mathrm{ml}$ by day 11); the combination of high-dose daptomycin and rifampicin was even more successful (a decrease in bacterial cell counts over $4.5 \log \mathrm{CFU} / \mathrm{mL}$ by day 11) and cured $94 \%$ of the animals whereas the standard dose of daptomycin $(6 \mathrm{mg} / \mathrm{kg} /$ day $)$ combined with rifampicin cured only two-thirds although being similarly bactericidal when compared to the highdose daptomycin combined with rifampicin in vitro [53]. However, in an in vitro model of biofilm with MRSA susceptible to daptomycin, monotherapy with daptomycin at a high dose $(10 \mathrm{mg} / \mathrm{kg} /$ day $)$ was only minimally effective in diminishing the biofilm cell counts within $72 \mathrm{~h}$ whereas the addition of rifampicin enhanced the bactericidal activity of daptomycin against bacteria in biofilm [54].

The reason for the discrepancy in rifampicin action among the results obtained in animal models of IE and foreign-body infection is not clear. Recently, Olson et al. proposed that rifampicin exerts the main bactericidal action on a biofilm while anti-staphylococcal antibiotics in the combination with rifampicin only prevent the outgrowth of rifampicin-resistant mutants which are known to emerge frequently and in high numbers during monotherapy with rifampicin in a laboratory setting [55].

5.2. Combinations of Daptomycin and Beta-Lactams. Combinations of daptomycin with beta-lactams have a basis in an observation that in some cases MRSA, which develops a diminished susceptibility to vancomycin or daptomycin, becomes more susceptible to oxacillin, a so-called "see-saw" effect [56]. An example of such pathogen is MDR S. aureus which becomes non-susceptible to daptomycin.

Various combinations have been tested in in vitro and animal models, most commonly daptomycin combined with a beta-lactam at a fraction of its MIC.

In in vitro time-kill experiments with MRSA susceptible to daptomycin, synergy was found between daptomycin at $0.5 \mathrm{MIC}$ and $32 \mathrm{mg} / \mathrm{L}$ oxacillin (oxacillin MIC for the majority of tested strains $\geq 256 \mathrm{mg} / \mathrm{l}$ ). Aminopenicillins, such as ampicillin, showed synergy at even lower concentrations $(2-8 \mathrm{mg} / \mathrm{l}$ ampicillin in a combination with ampicillin/sulbactam) [57].

Similarly, addition of subtherapeutic levels of betalactams to daptomycin delayed or prevented the emergence of diminished susceptibility to daptomycin in in vitro selection studies performed on four homogenously daptomycin susceptible MRSA which were also vancomycin-susceptible (VSSA) and two heterogeneously daptomycin susceptible and methicillin-resistant GISA strains. The MICs increased 2-4 times over the baseline in case of MRSA and only twofold in case of GISA [58], which is substantially less than that seen after several passages of $S$. aureus in subinhibitory concentrations of daptomycin alone [12, 16, 17]. The effect was the most pronounced in case of aminopenicillins, such as ampicillin or amoxicillin/clavulanic acid [58].

Interestingly, in an in vitro pharmacodynamic model of IE with simulated endocardial vegetations, the combination of daptomycin $6 \mathrm{mg} / \mathrm{kg} /$ day with cefepime $2 \mathrm{~g}$ bid was superior to daptomycin monotherapy in eradication of MRSA/VSSA but not of MRSA/hVISA [59]. Both strains were heterogeneously non-susceptible to daptomycin with the former having two-fold higher MIC than the latter.

In in vitro time-kill assays using clinical strains of $S$. aureus which developed non-susceptibility during treatment (daptomycin MIC 2-4 mg/L) and one in vitro selected nonsusceptible strain (MIC $8 \mathrm{mg} / \mathrm{L}$ ), treatment with a combination of daptomycin and oxacillin at 0.25 MIC showed modest increase of in vitro oxacillin bactericidal activity within 4-6 hours (1-2 log CFU/mL decrease in cell counts). An in vivo study of a rabbit model of aortic IE was then 
TABLE 3: In vitro synergy of antibiotic combinations.

\begin{tabular}{|c|c|c|c|c|}
\hline Method & Strain & Combination & Observation & Ref. \\
\hline Etest and time-kill study & hGISA/MSSA & $\begin{array}{l}\text { Daptomycin with } \\
\text { vancomycin, } \\
\text { gentamicin, rifampin, } \\
\text { linezolid, } \\
\text { quinupristin/ } \\
\text { dalfopristin, } \\
\text { ampicilin-sulbactam }\end{array}$ & $\begin{array}{l}\text { Etest: additive effect with daptomycin }+ \\
\text { vancomycin and daptomycin + gentamycin, } \\
\text { other combinations with daptomycin } \\
\text { indifferent } \\
\text { Time-kill study: additive effect with } \\
\text { daptomycin + gentamycin, other } \\
\text { combinations with daptomycin indifferent }\end{array}$ & {$[40]$} \\
\hline Etest and time-kill study & GISA/MRSA & $\begin{array}{l}\text { Daptomycin with } \\
\text { vancomycin, } \\
\text { gentamicin, rifampin, } \\
\text { linezolid, } \\
\text { quinopristine/ } \\
\text { dalfopristine, } \\
\text { ampicilin-sulbactam }\end{array}$ & $\begin{array}{l}\text { Etest: additive effect only with daptomycin } \\
\text { + gentamycin, other combinations with } \\
\text { daptomycin indifferent } \\
\text { Time-kill study: indifference }\end{array}$ & {$[40]$} \\
\hline Time-kill study & MRSA & $\begin{array}{l}\text { Daptomycin }+ \\
\text { gentamicin }\end{array}$ & Synergy in all three strains & {$[41]$} \\
\hline Time-kill study & MRSA & $\begin{array}{l}\text { Daptomycin }+ \\
\text { rifampin }\end{array}$ & $\begin{array}{l}\text { Antagonism in one strain and indifference } \\
\text { in two other strains }\end{array}$ & [41] \\
\hline Time-kill study & MRSA & $\begin{array}{l}\text { Daptomycin at } 0.0625 \\
\text { MIC to } 2 \text { MIC }+ \\
\text { oxacillin or } \\
\text { ampicillin- sulbactam }\end{array}$ & $\begin{array}{l}\text { Synergy of daptomycin at } 0.5 \mathrm{MIC}+ \\
\text { oxacillin } 32 \mathrm{mg} / \mathrm{L} \text { or ampicillin-sulbactam } \\
2-8 \mathrm{mg} / \mathrm{L} \text { (ampicillin) }\end{array}$ & [57] \\
\hline In vitro model of biofilm & MSSA & $\begin{array}{l}\text { Daptomycin } \\
10 \mathrm{mg} / \mathrm{kg} / \mathrm{d}+ \\
\text { clarithromycin } \\
250 \mathrm{mg} \mathrm{q} 12 \mathrm{~h}\end{array}$ & $\begin{array}{l}\text { Sustained bactericidal activity against } \\
\text { planctonic and biofilm bacteria }\end{array}$ & [54] \\
\hline In vitro model of biofilm & MRSA & $\begin{array}{l}\text { Daptomycin } \\
10 \mathrm{mg} / \mathrm{kg} / \mathrm{d}+ \\
\text { rifampin at } 600 \mathrm{mg} \\
\mathrm{q} 24 \mathrm{~h}\end{array}$ & $\begin{array}{l}\text { Sustained bactericidal activity against } \\
\text { planctonic and biofilm bacteria }\end{array}$ & [54] \\
\hline $\begin{array}{l}\text { In vitro selection for } \\
\text { resistance }\end{array}$ & $\begin{array}{l}\text { MRSA and } \\
\text { GISA }\end{array}$ & $\begin{array}{l}\text { Daptomycin }+0.25 \\
\text { MIC ampicillin, } \\
\text { amoxicillin-clavulanic } \\
\text { acid, gentamicin, } \\
\text { rifampin }\end{array}$ & $\begin{array}{l}\text { Combination with ampicillin, } \\
\text { amoxicillin-clavulanic acid } \\
\text { delayed/prevented occurrence of } \\
\text { non-susceptibility; rifampin delayed } \\
\text { non-susceptibility }\end{array}$ & [58] \\
\hline Checkerboard method & MRSA, MSSA & $\begin{array}{l}\text { Daptomycin }+ \\
\text { rifampicin, } \\
\text { moxifloxacin or } \\
\text { fusidic acid }\end{array}$ & $\begin{array}{l}\text { Daptomycin + fusidic acid: antagonism in } \\
\text { one MSSA strain reported }\end{array}$ & {$[68]$} \\
\hline
\end{tabular}

MRSA: meticillin-resistant S. aureus; MSSA: meticillin-susceptible S. aureus; GISA: glycopeptide-intermediate S. aureus; hGISA: heteroresistant glycopeptideintermediate S. aureus; MIC: minimal inhibitory concentration (mg/L).

performed using initial daptomycin susceptible and nonsusceptible clinical MRSA isolates. An increased bactericidal effect of the combination on the daptomycin non-susceptible S. aureus strains was established; it was more pronounced in vivo than in vitro. For the daptomycin-susceptible parental strains, the combination treatment with beta-lactams was not studied because daptomycin alone was found to be sufficiently bactericidal to cure the infection [56]. In spite of the observed "see-saw" effect (increased susceptibility to oxacillin) in daptomycin non-susceptible strains oxacillin monotherapy was not successful. All examined strains retained mecA gene.

5.3. Combinations of Daptomycin with Bacteriostatic Antibiotics. A somewhat unusual combination of daptomycin and
TMP-SMX was studied in an in vitro pharmacodynamic model of IE with simulated endocardial vegetations. The TMP-SMX monotherapy was found inferior to the standard treatment of $S$. aureus IE [60]. The combination of daptomycin at $6 \mathrm{mg} / \mathrm{kg} / \mathrm{day}$ and TMP-SMX at 160/800 mg bid was more rapidly bactericidal against daptomycin nonsusceptible strains of $S$. aureus than daptomycin alone [59].

The efficacy of combination of clarithromycin and a beta-lactam or vancomycin for eradication of $S$. aureus biofilms has already been demonstrated [61]. A similar increase in bactericidal activity was observed in an in vitro model of biofilm using an MSSA strain. The combination of daptomycin $10 \mathrm{mg} / \mathrm{kg} /$ day and clarithromycin $250 \mathrm{mg}$ bid was more effective in eradication of bacteria in the biofilm than daptomycin alone [53]. 
The mechanism behind the efficacy of some of the unusual combinations of antibiotics presented in this review is not clear. A concept of a mutant prevention concentration and mutant selection window hypothesis was proposed a decade ago [62]. Mutant prevention concentration is defined as the minimal concentration of antibiotic at which no single-step resistant mutants are recovered on agar plates when plated at high inoculum ( $>10^{10}$ cells) [62] while mutant selection window denotes a window between $\mathrm{MIC}_{99}$ and mutant prevention concentration in which resistant mutants are enriched $\left(\mathrm{MIC}_{99} /\right.$ mutant prevention concentration) [63]. It is thought to represent the MICs of susceptible and single-step resistant mutants. Both parameters are agent and bacterial-strain dependent. Mutant selection window is in some cases small with mutant prevention concentration well below the clinically achievable antibiotic concentrations, such as those of penicillin in case of MSSA. On the other hand, mutant selection window of rifampicin for MSSA is very broad $(160,000)$ with mutant prevention concentration of $480 \mathrm{mg} / \mathrm{L}$ [63] which is far too high for clinical use. This may explain the high resistance observed in the laboratory. Combined treatment with two or more antibiotics may have a lower mutant prevention concentration, since two or more concomitant resistance mutations are necessary for growth; thus, reaching concentrations of antibiotics that exceed mutant prevention concentration is then feasible in a clinical setting [63]. Mutant selection window hypothesis has been confirmed for daptomycin in vitro, where the mutant selection window is about $2-5$ with clinically achievable concentrations well above the mutant prevention concentration with a currently highest approved daily dose of $6 \mathrm{mg} / \mathrm{kg}$ $[64,65]$. Nevertheless, with the high protein binding of daptomycin [4], the observed development of non-susceptibility in vitro and in clinical cases at a dose of $6 \mathrm{mg} / \mathrm{kg} /$ day suggests that the effective free drug concentrations are lower (as much as 90\%) and that mutant prevention concentration is not reached. This speculation is further strengthened by the success of high doses of daptomycin $(10 \mathrm{mg} / \mathrm{kg} /$ day $)$, which are, even so, not approved by regulatory agencies for clinical use. A combination of daptomycin with other antibiotics may lower the mutant prevention concentration as has already been described for tobramycin-rifampicin combination [63].

\section{Conclusions and Future Outlook}

We have discussed combinations of daptomycin with other antibiotics, a new therapeutic strategy for treatment of complicated infections with $S$. aureus. Classical combination of daptomycin with rifampicin seems to be effective only for foreign-body infections while data for IE is somewhat contradictory. Combinations of daptomycin with beta-lactams, TMP-SMX, or clarithromycin provide a fresh strategy in combating infections with MDR S. aureus; the value of the new approaches is supported by the findings of in vitro and in vivo studies but is yet to be assessed and proven in clinical settings.

\section{References}

[1] V. G. Fowler, H. W. Boucher, G. R. Corey et al., "Daptomycin versus standard therapy for bacteremia and endocarditis caused by Staphylococcus aureus," The New England Journal of Medicine, vol. 355, no. 7, pp. 653-665, 2006.

[2] P. E. Pertel, P. Bernardo, C. Fogarty et al., "Effects of prior effective therapy on the efficacy of daptomycin and ceftriaxone for the treatment of community-acquired pneumonia," Clinical Infectious Diseases, vol. 46, no. 8, pp. 1142-1151, 2008.

[3] J. A. Silverman, N. G. Perlmutter, and H. M. Shapiro, "Correlation of daptomycin bactericidal activity and membrane depolarization in Staphylococcus aureus," Antimicrobial Agents and Chemotherapy, vol. 47, no. 8, pp. 2538-2544, 2003.

[4] D. A. Enoch, J. M. Bygott, M. L. Daly, and J. A. Karas, "Daptomycin," Journal of Infection, vol. 55, no. 3, pp. 205-213, 2007.

[5] S. K. Straus and R. E. W. Hancock, "Mode of action of the new antibiotic for Gram-positive pathogens daptomycin: comparison with cationic antimicrobial peptides and lipopeptides," Biochimica et Biophysica Acta, vol. 1758, no. 9, pp. 1215-1223, 2006.

[6] J. K. Hobbs, K. Miller, A. J. O’Neill, and I. Chopra, “Consequences of daptomycin-mediated membrane damage in Staphylococcus aureus," Journal of Antimicrobial Chemotherapy, vol. 62 , no. 5, pp. 1003-1008, 2008.

[7] N. Cotroneo, R. Harris, N. Perlmutter, T. Beveridge, and J. A. Silverman, "Daptomycin exerts bactericidal activity without lysis of Staphylococcus aureus," Antimicrobial Agents and Chemotherapy, vol. 52, no. 6, pp. 2223-2225, 2008.

[8] A. Muthaiyan, J. A. Silverman, R. K. Jayaswal, and B. J. Wilkinson, "Transcriptional profiling reveals that daptomycin induces the Staphylococcus aureus cell wall stress stimulon and genes responsive to membrane depolarization," Antimicrobial Agents and Chemotherapy, vol. 52, no. 3, pp. 980-990, 2008.

[9] K. L. LaPlante and M. J. Rybak, "Impact of high-inoculum Staphylococcus aureus on the activities of nafcillin, vancomycin, linezolid, and daptomycin, alone and in combination with gentamicin, in an in vitro pharmacodynamic model," Antimicrobial Agents and Chemotherapy, vol. 48, no. 12, pp. 4665-4672, 2004.

[10] K. I. Udekwu, N. Parrish, P. Ankomah, F. Baquero, and B. R. Levin, "Functional relationship between bacterial cell density and the efficacy of antibiotics," Journal of Antimicrobial Chemotherapy, vol. 63, no. 4, pp. 745-757, 2009.

[11] M. D. Appleman and D. M. Citron, "Efficacy of vancomycin and daptomycin against Staphylococcus aureus isolates collected over 29 years," Diagnostic Microbiology and Infectious Disease, vol. 66, no. 4, pp. 441-444, 2010.

[12] J. A. Silverman, N. Oliver, T. Andrew, and T. Li, "Resistance studies with daptomycin," Antimicrobial Agents and Chemotherapy, vol. 45, no. 6, pp. 1799-1802, 2001.

[13] G. Steinkraus, R. White, and L. Friedrich, "Vancomycin MIC creep in non-vancomycin-intermediate Staphylococcus aureus (VISA), vancomycin-susceptible clinical methicillin-resistant S. aureus (MRSA) blood isolates from 2001-2005," Journal of Antimicrobial Chemotherapy, vol. 60, no. 4, pp. 788-794, 2007.

[14] D. M. Anastasiou, M. Morgan, P. J. Ruane et al., "In vitro activity of daptomycin against multidrug-resistant Staphylococcus aureus and $S$. aureus with known virulence factors, including community-acquired methicillin-resistant isolates," Diagnostic Microbiology and Infectious Disease, vol. 61, no. 3, pp. 339-342, 2008. 
[15] R. Cha and M. J. Rybak, "Daptomycin against multiple drugresistant staphylococcus and enterococcus isolates in an in vitro pharmacodynamic model with simulated endocardial vegetations," Diagnostic Microbiology and Infectious Disease, vol. 47, no. 3, pp. 539-546, 2003.

[16] L. Friedman, J. D. Alder, and J. A. Silverman, "Genetic changes that correlate with reduced susceptibility to daptomycin in Staphylococcus aureus," Antimicrobial Agents and Chemotherapy, vol. 50, no. 6, pp. 2137-2145, 2006.

[17] G. W. Kaatz, T. S. Lundstrom, and S. M. Seo, "Mechanisms of daptomycin resistance in Staphylococcus aureus," International Journal of Antimicrobial Agents, vol. 28, no. 4, pp. 280-287, 2006.

[18] I. L. B. da Cunha Camargo, H. M. Neoh, L. Cui, and K. Hiramatsu, "Serial daptomycin selection generates daptomycinnonsusceptible Staphylococcus aureus strains with a heterogeneous vancomycin-intermediate phenotype," Antimicrobial Agents and Chemotherapy, vol. 52, no. 12, pp. 4289-4299, 2008.

[19] S.-J. Yang, C. C. Nast, N. N. Mishra, M. R. Yeaman, P. D. Fey, and A. S. Bayer, "Cell wall thickening is not a universal accompaniment of the daptomycin nonsusceptibility phenotype in Staphylococcus aureus: evidence for multiple resistance mechanisms," Antimicrobial Agents and Chemotherapy, vol. 54, no. 8, pp. 3079-3085, 2010.

[20] N. N. Mishra, S. J. Yang, A. Sawa et al., "Analysis of cell membrane characteristics of in vitro-selected daptomycinresistant strains of methicillin-resistant Staphylococcus aureus," Antimicrobial Agents and Chemotherapy, vol. 53, no. 6, pp. 2312-2318, 2009.

[21] L. Cui, T. Isii, M. Fukuda et al., "A RpoB mutation confers dual hetero-resistance to daptomycin and vancomycin in Staphylococcus aureus," Antimicrobial Agents and Chemotherapy, vol. 54, pp. 5222-5233, 2010.

[22] B. D. Duval, A. Mathew, S. W. Satola, and W. M. Shafer, "Altered growth, pigmentation, and antimicrobial susceptibility properties of Staphylococcus aureus due to loss of the major cold shock gene cspB," Antimicrobial Agents and Chemotherapy, vol. 54, no. 6, pp. 2283-2290, 2010.

[23] W. E. Rose, S. N. Leonard, and M. J. Rybak, "Evaluation of daptomycin pharmacodynamics and resistance at various dosage regimens against Staphylococcus aureus isolates with reduced susceptibilities to daptomycin in an in vitro pharmacodynamic model with simulated endocardial vegetations," Antimicrobial Agents and Chemotherapy, vol. 52, no. 9, pp. 3061-3067, 2008.

[24] S. K. Pillai, H. S. Gold, G. Sakoulas, C. Wennersten, R. C. Moellering, and G. M. Eliopoulos, "Daptomycin nonsusceptibility in Staphylococcus aureus with reduced vancomycin susceptibility is independent of alterations in MprF," Antimicrobial Agents and Chemotherapy, vol. 51, no. 6, pp. 22232225, 2007.

[25] L. Cui, E. Tominaga, H. M. Neoh, and K. Hiramatsu, "Correlation between reduced daptomycin susceptibility and vancomycin resistance in vancomycin-intermediate Staphylococcus aureus," Antimicrobial Agents and Chemotherapy, vol. 50, no. 3, pp. 1079-1082, 2006.

[26] T. Jones, M. R. Yeaman, G. Sakoulas et al., "Failures in clinical treatment of Staphylococcus aureus infection with daptomycin are associated with alterations in surface charge, membrane phospholipid asymmetry, and drug binding," Antimicrobial Agents and Chemotherapy, vol. 52, no. 1, pp. 269-278, 2008.
[27] Y. T. Huang, C. H. Hsiao, C. H. Liao, C. W. Lee, and P. R. Hsueh, "Bacteremia and infective endocarditis caused by a non-daptomycin- susceptible, vancomycin-intermediate, and methicillin-resistant Staphylococcus aureus strain in Taiwan," Journal of Clinical Microbiology, vol. 46, no. 3, pp. 1132-1136, 2008.

[28] N. Høiby, T. Bjarnsholt, M. Givskov, S. Molin, and O. Ciofu, "Antibiotic resistance of bacterial biofilms," International Journal of Antimicrobial Agents, vol. 35, no. 4, pp. 322-332, 2010.

[29] J. C. Hageman, J. Patel, P. Franklin et al., "Occurrence of a USA300 vancomycin-intermediate Staphylococcus aureus," Diagnostic Microbiology and Infectious Disease, vol. 62, no. 4, pp. 440-442, 2008.

[30] F. C. Tenover, S. W. Sinner, R. E. Segal et al., "Characterisation of a Staphylococcus aureus strain with progressive loss of susceptibility to vancomycin and daptomycin during therapy," International Journal of Antimicrobial Agents, vol. 33, no. 6, pp. 564-568, 2009.

[31] J. W. Bennett, C. K. Murray, R. L. Holmes, J. E. Patterson, and J. H. Jorgensen, "Diminished vancomycin and daptomycin susceptibility during prolonged bacteremia with methicillinresistant Staphylococcus aureus," Diagnostic Microbiology and Infectious Disease, vol. 60, no. 4, pp. 437-440, 2008.

[32] G. Sakoulas, J. Alder, C. Thauvin-Eliopoulos, R. C. Moellering, and G. M. Eliopoulos, "Induction of daptomycin heterogeneous susceptibility in Staphylococcus aureus by exposure to vancomycin," Antimicrobial Agents and Chemotherapy, vol. 50, no. 4, pp. 1581-1585, 2006.

[33] P.-R. Hsueh, S.-Y. Lee, C.-L. Perng, T.-Y. Chang, and J.-J. Lu, "Clonal dissemination of meticillin-resistant and vancomycinintermediate Staphylococcus aureus in a Taiwanese hospital," International Journal of Antimicrobial Agents, vol. 36, no. 4, pp. 307-312, 2010.

[34] S. K. Pillai, C. Wennersten, L. Venkataraman, G. M. Eliopoulos, R. C. Moellering, and A. W. Karchmer, "Development of reduced vancomycin susceptibility in methicillin-susceptible Staphylococcus aureus," Clinical Infectious Diseases, vol. 49, no. 8, pp. 1169-1174, 2009.

[35] P. A. Moise, D. S. Smyth, N. El-fawal et al., "Microbiological effects of prior vancomycin use in patients with methicillin-resistant Staphylococcus aureus bacteraemia," Journal of Antimicrobial Chemotherapy, vol. 61, no. 1, pp. 85-90, 2008.

[36] The Task Force on the Prevention, Diagnosis, and Treatment of Infective Endocarditis of the European Society of Cardiology (ESC), "Guidelines on the prevention, diagnosis, and treatment of infective endocarditis," European Heart Journal, vol. 30, pp. 2369-2413, 2009.

[37] D. P. Levine and K. C. Lamp, "Daptomycin in the treatment of patients with infective endocarditis: experience from a registry," American Journal of Medicine, vol. 120, no. 10, pp. S28-S33, 2007.

[38] J. A. Crompton, D. S. North, M. Yoon, J. N. Steenbergen, K. C. Lamp, and G. N. Forrest, "Outcomes with daptomycin in the treatment of Staphylococcus aureus infections with a range of vancomycin MICs," Journal of Antimicrobial Chemotherapy, vol. 65, no. 8, pp. 1784-1791, 2010.

[39] K. L. LaPlante and S. Woodmansee, "Activities of daptomycin and vancomycin alone and in combination with rifampin and gentamicin against biofilm-forming methicillin-resistant 
Staphylococcus aureus isolates in an experimental model of endocarditis," Antimicrobial Agents and Chemotherapy, vol. 53, no. 9, pp. 3880-3886, 2009.

[40] B. T. Tsuji and M. J. Rybak, "Etest synergy testing of clinical isolates of Staphylococcus aureus demonstrating heterogeneous resistance to vancomycin," Diagnostic Microbiology and Infectious Disease, vol. 54, no. 1, pp. 73-77, 2006.

[41] J. M. Miró, C. García-de-la-Mària, Y. Armero et al., "Addition of gentamicin or rifampin does not enhance the effectiveness of daptomycin in treatment of experimental endocarditis due to methicillin- resistant Staphylococcus aureus," Antimicrobial Agents and Chemotherapy, vol. 53, no. 10, pp. 4172-4177, 2009.

[42] M. Lichterfeld, M. J. Ferraro, and B. T. Davis, "Highdose daptomycin for the treatment of endocarditis caused by Staphylococcus aureus with intermediate susceptibility to glycopeptides," International Journal of Antimicrobial Agents, vol. 35, no. 1, article 96, 2010.

[43] J. L. Del Pozo and R. Patel, "Infection associated with prosthetic joints," The New England Journal of Medicine, vol. 361, no. 8, pp. 787-794, 2009.

[44] W. Zimmerli, A. Trampuz, and P. E. Ochsner, "Current concepts: prosthetic-joint infections," The New England Journal of Medicine, vol. 351, no. 16, pp. 1645-1654, 2004.

[45] W. Zimmerli, A. F. Widmer, M. Blatter, R. Frei, and P. E. Ochsner, "Role of rifampin for treatment of orthopedic implant-related staphylococcal infections: a randomized controlled trial," Journal of the American Medical Association, vol. 279, no. 19, pp. 1537-1541, 1998.

[46] R. Singh, P. Ray, A. Das, and M. Sharma, "Penetration of antibiotics through Staphylococcus aureus and Staphylococcus epidermidis biofilms," Journal of Antimicrobial Chemotherapy, vol. 65, no. 9, pp. 1955-1958, 2010.

[47] Z. Zheng and P. S. Stewart, "Penetration of rifampin through Staphylococcus epidermidis biofilms," Antimicrobial Agents and Chemotherapy, vol. 46, no. 3, pp. 900-903, 2002.

[48] P. S. Stewart, W. M. Davison, and J. N. Steenbergen, "Daptomycin rapidly penetrates a Staphylococcus epidermidis biofilm," Antimicrobial Agents and Chemotherapy, vol. 53, no. 8, pp. 3505-3507, 2009.

[49] P. Vaudaux, P. Francois, C. Bisognano, D. Li, D. P. Lew, and J. Schrenzel, "Comparative efficacy of daptomycin and vancomycin in the therapy of experimental foreign body due to Staphylococcus aureaus," Journal of Antimicrobial Chemotherapy, vol. 52, no. 1, pp. 89-95, 2003.

[50] M. Lefebvre, C. Jacqueline, G. Amador et al., "Efficacy of daptomycin combined with rifampicin for the treatment of experimental meticillin-resistant Staphylococcus aureus (MRSA) acute osteomyelitis," International Journal of Antimicrobial Agents, vol. 36, no. 6, pp. 542-544, 2010.

[51] A. K. John, D. Baldoni, M. Haschke et al., "Efficacy of daptomycin in implant-associated infection due to methicillinresistant Staphylococcus aureus: importance of combination with rifampin," Antimicrobial Agents and Chemotherapy, vol. 53, no. 7, pp. 2719-2724, 2009.

[52] O. Murillo, C. Garrigós, M. E. Pachón et al., "Efficacy of high doses of daptomycin versus alternative therapies against experimental foreign-body infection by methicillin-resistant Staphylococcus aureus," Antimicrobial Agents and Chemotherapy, vol. 53, no. 10, pp. 4252-4257, 2009.

[53] C. Garrigós, O. Murillo, G. Euba et al., "Efficacy of usual and high doses of daptomycin in combination with rifampin versus alternative therapies in experimental foreign-body infection by methicillin-resistant Staphylococcus aureus," Antimicrobial Agents and Chemotherapy, vol. 54, no. 12, pp. 5251-5256, 2010.

[54] J. Parra-Ruiz, C. Vidaillac, W. E. Rose, and M. J. Rybak, "Activities of high-dose daptomycin, vancomycin, and moxifloxacin alone or in combination with clarithromycin or rifampin in a novel in vitro model of Staphylococcus aureus biofilm," Antimicrobial Agents and Chemotherapy, vol. 54, no. 10, pp. 4329-4334, 2010.

[55] M. E. Olson, S. R. Slater, M. E. Rupp, and P. D. Fey, "Rifampicin enhances activity of daptomycin and vancomycin against both a polysaccharide intercellular adhesin (PIA)dependent and -independent Staphylococcus epidermidis biofilm," Journal of Antimicrobial Chemotherapy, vol. 65, no. 10, pp. 2164-2171, 2010.

[56] S.-J. Yang, Y. Q. Xiong, S. Boyle-Vavra, R. Daum, T. Jones, and A. S. Bayer, "Daptomycin-oxacillin combinations in treatment of experimental endocarditis caused by daptomycinnonsusceptible strains of methicillin-resistant Staphylococcus aureus with evolving oxacillin susceptibility (the "seesaw effect")," Antimicrobial Agents and Chemotherapy, vol. 54, no. 8, pp. 3161-3169, 2010.

[57] K. H. Rand and H. J. Houck, "Synergy of daptomycin with oxacillin and other $\beta$-lactams against methicillin-resistant Staphylococcus aureus," Antimicrobial Agents and Chemotherapy, vol. 48, no. 8, pp. 2871-2875, 2004.

[58] J. M. Entenza, M. Giddey, J. Vouillamoz, and P. Moreillon, "In vitro prevention of the emergence of daptomycin resistance in Staphylococcus aureus and enterococci following combination with amoxicillin/clavulanic acid or ampicillin," International Journal of Antimicrobial Agents, vol. 35, no. 5, pp. 451-456, 2010.

[59] M. E. Steed, C. Vidaillac, and M. J. Rybak, "Novel daptomycin combinations against daptomycin-nonsusceptible methicillin-resistant Staphylococcus aureus in an in vitro model of simulated endocardial vegetations," Antimicrobial Agents and Chemotherapy, vol. 54, no. 12, pp. 5187-5192, 2010.

[60] M. De Gorgolas, P. Aviles, C. Verdejo, and M. L. F. Guerrero, "Treatment of experimental endocarditis due to methicillinsusceptible or methicillin-resistant Staphylococcus aureus with trimethoprim- sulfamethoxazole and antibiotics that inhibit cell wall synthesis," Antimicrobial Agents and Chemotherapy, vol. 39, no. 4, pp. 953-957, 1995.

[61] S. Fujimura, T. Sato, T. Mikami, T. Kikuchi, K. Gomi, and A. Watanabe, "Combined efficacy of clarithromycin plus cefazolin or vancomycin against Staphylococcus aureus biofilms formed on titanium medical devices," International Journal of Antimicrobial Agents, vol. 32, no. 6, pp. 481-484, 2008.

[62] G. Sindelar, X. Zhao, A. Liew et al., "Mutant prevention concentration as a measure of fluoroquinolone potency against mycobacteria," Antimicrobial Agents and Chemotherapy, vol. 44, no. 12, pp. 3337-3343, 2000.

[63] X. Zhao and K. Drlica, "Restricting the selection of antibioticresistant mutant bacteria: measurement and potential use of the mutant selection window," Journal of Infectious Diseases, vol. 185, no. 4, pp. 561-565, 2002.

[64] A. A. Firsov, M. V. Smirnova, I. Y. Lubenko, S. N. Vostrov, Y. A. Portnoy, and S. H. Zinner, "Testing the mutant selection window hypothesis with Staphylococcus aureus exposed to daptomycin and vancomycin in an in vitro dynamic model," 
Journal of Antimicrobial Chemotherapy, vol. 58, no. 6, pp. 1185-1192, 2006.

[65] B. Quinn, S. Hussain, M. Malik, K. Drlica, and X. Zhao, "Daptomycin inoculum effects and mutant prevention concentration with Staphylococcus aureus," Journal of Antimicrobial Chemotherapy, vol. 60, no. 6, pp. 1380-1383, 2007.

[66] B. T. Tsuji and M. J. Rybak, "Short-course gentamicin in combination with daptomycin or vancomycin against Staphylococcus aureus in an in vitro pharmacodynamic model with simulated endocardial vegetations," Antimicrobial Agents and Chemotherapy, vol. 49, no. 7, pp. 2735-2745, 2005.

[67] R. L. Akins and M. J. Rybak, "In vitro activities of daptomycin, arbekacin, vancomycin, and gentamicin alone and/or in combination against glycopeptide intermediate-resistant Staphylococcus aureus in an infection model," Antimicrobial Agents and Chemotherapy, vol. 44, no. 7, pp. 1925-1929, 2000.

[68] B. Kuli, B. de Barbeyrac, F. A. Dauchy et al., "In vitro activities of daptomycin, tigecycline, linezolid and eight other antibiotics, alone and in combination, against 41 Staphylococcus spp. clinical isolates from bone and joint infections," International Journal of Antimicrobial Agents, vol. 33, no. 5, pp. 491-493, 2009. 


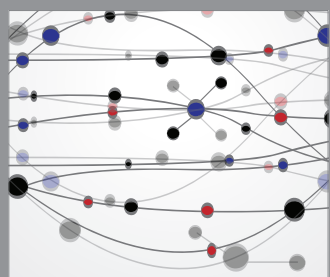

The Scientific World Journal
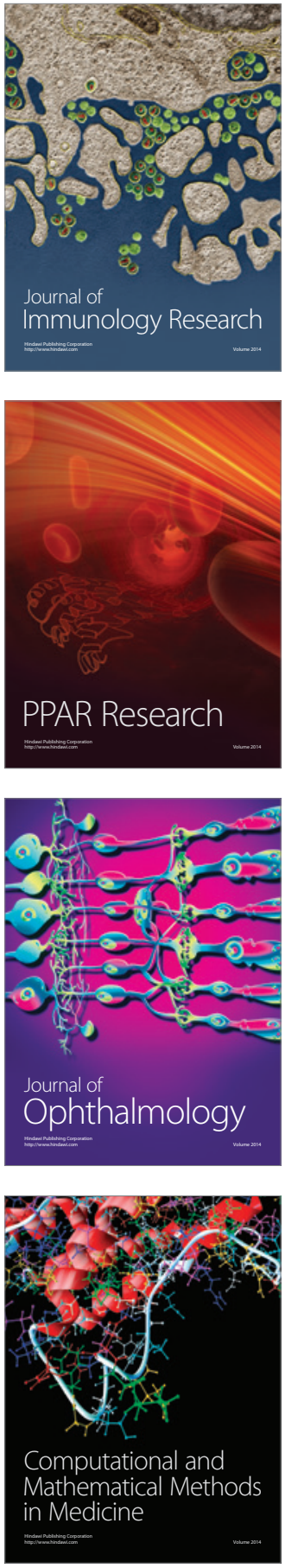

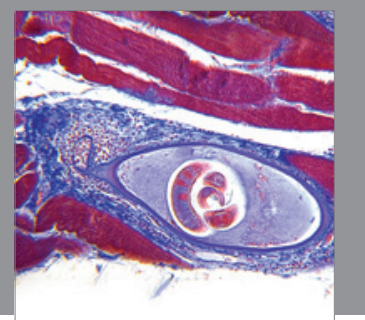

Gastroenterology

Research and Practice
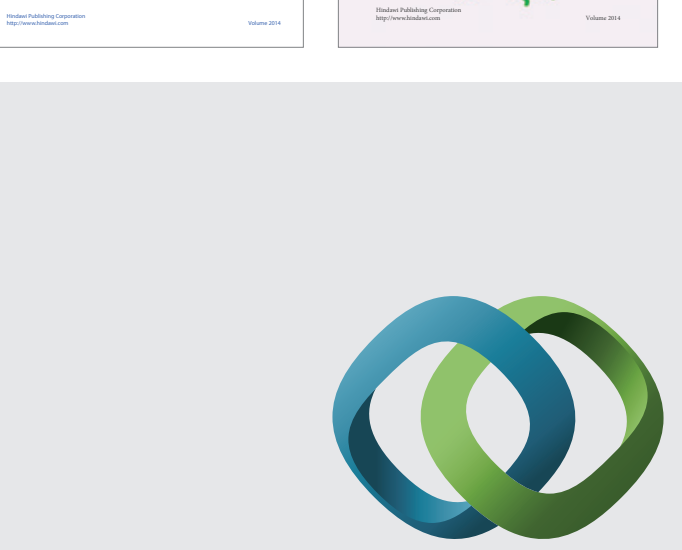

\section{Hindawi}

Submit your manuscripts at

http://www.hindawi.com
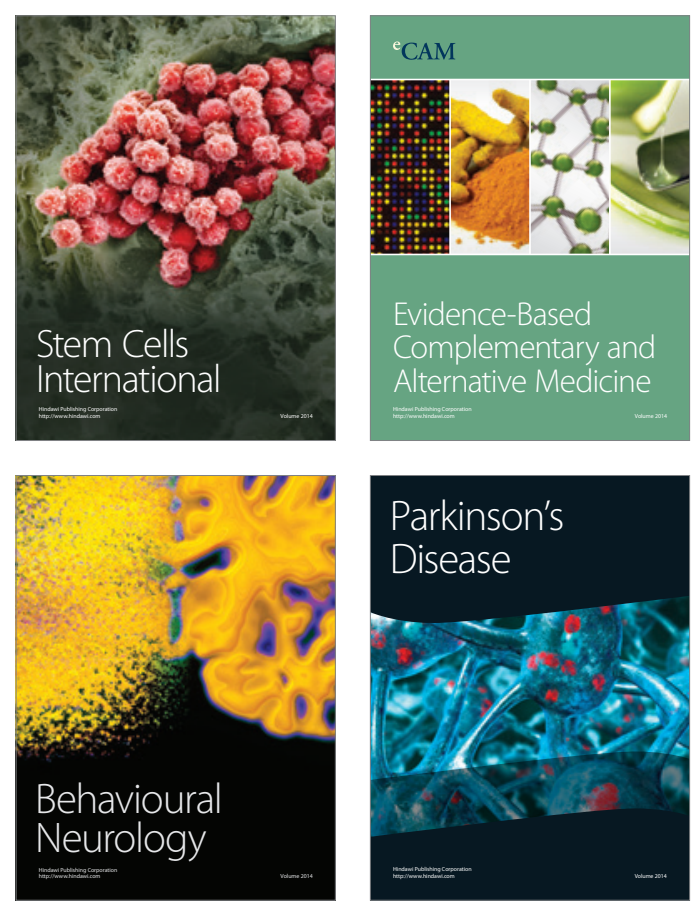

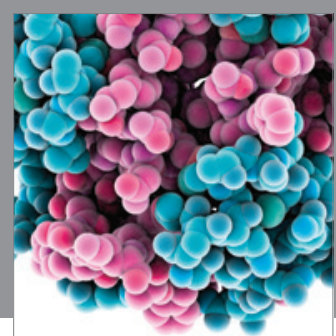

Journal of
Diabetes Research

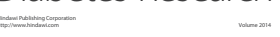

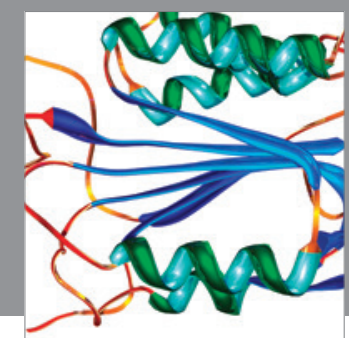

Disease Markers
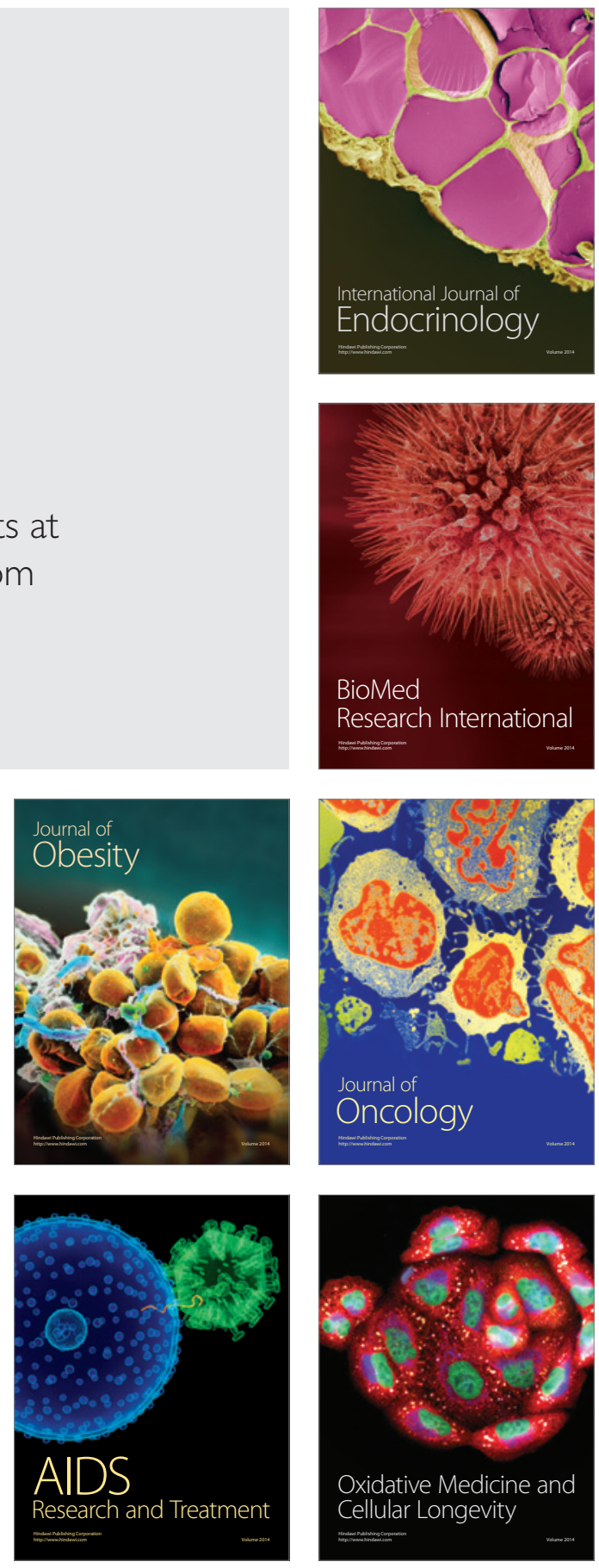